REVISTA DE ESTUDIOS E INVESTIGACIÓN EN PSICOLOGÍA Y EDUCACIÓN

\title{
La autobiografía como metodología visual introspectiva en la investigación en Educación Artística
}

\section{Autobiography as an introspective and visual methodology in Art Education Research}

Tiffany López-Ganet (iD https://orcid.org/0000-0003-1467-8181

Universidad de Granada: https://www.ugr.es/

A Coruña - España

José María Mesías-Lema (iD https://orcid.org/0000-0001-8278-7115

Universidad de A Coruña: https://www.udc.es/

A Coruña - España 


\title{
Resumen
}

El presente trabajo de Investigación Educativa Basada en las Artes pretende mostrar las posibilidades metodológicas de la autobiografía en el campo de la Educación Artística. A través de una introspección personal se genera, utilizando metodologías artísticas a través de instrumentos de investigación como las fotografías de los álbumes familiares, archivos audiovisuales domésticos o el propio diario, una reflexión de la que extraer estrategias artísticas de investigación para usar en el aula. Los instrumentos de investigación como el diario, la fotografía o el vídeo suponen el punto de partida de la reflexión personal del profesorado, materializan su búsqueda, documentan el proceso de la investigación y son la vía para compartirlo con el alumnado por medio de estrategias decoloniales que fomenten la empatía. Incorporar las historias de vida del profesorado y del alumnado y convertirlas en el eje vertebrador de la planificación, desarrollo y reflexión de las acciones artísticas permite emprender un viaje desde lo más individual e íntimo hasta lo común y colectivo que fortalece lazos y permite una evolución orgánica del proceso investigador.

Palabras clave: Investigación Basada en las Artes; autobiografía; formación docente; educación artística; archivo fotográfico doméstico

\begin{abstract}
This Art-based Educational Research work pretends to show the methodological possibilities of the autobiography in the Art Education field. A reflection is generated through a personal introspection, using artistic methodologies with research tools such as photographs from family albums, domestic videos or the own diary. From this personal reflection, artistic research strategies are extrapolated to use them in the classroom. Research tools such as photography and video are the starting point of the teachers' personal reflection, they objectify their search, these research tools also document the research process and they are even the way of sharing it with the students through decolonial strategies which promote empathy. Including the live stories of teachers and students and making them the backbone of planning, developing and reflection of the artistic actions allows for undertaking a journey from the most individual and intimate to the common and collective; a journey which strengthens ties and allows an organic evolution of the research process.
\end{abstract}

Keywords: Art-Based Research; autobiography; teaching training; art education; domestic photographic archive 


\section{Punto de partida: la importancia de la conexión del profesorado con su contexto sociocultural}

Compartir nuestras propias experiencias e historias de vida nos libera, sana y conciencia, permitiéndonos hablar de realidades colectivas desde las individuales e integrar lo personal y subjetivo en un discurso académico. El diario, la fotografía y el vídeo del archivo fotográfico familiar $-y$ toda la reflexión interior que pueden provocar - se convierten en elementos primordiales para la producción artística capaz de articular respuestas metodológicas en contextos educativos. Estos instrumentos de investigación artística documentan el proceso y validan la investigación: un viaje personal a través de la memoria que busca conectar las narrativas personales y biográficas de docentes e investigadores con su contexto sociocultural con vistas a construir en colectivo una posible transformación social.

El presente trabajo de investigación parte de la necesidad de hallar un vínculo entre el arteducador y la realidad que le rodea y de la importancia de hacer partícipe de esta búsqueda al alumnado. Analizados trabajos previos sobre la incorporación de las historias de vida tanto del profesorado como del alumnado en el aula, se ha comprobado lo difícil que es relatar esas autobiografías y compartir la búsqueda. Una de las aportaciones de esta investigación espera ser el mostrar las posibilidades de la historia de vida como elemento vertebrador de las acciones posteriores en el aula, creando una conexión entre las personas involucradas en ellas.

A pesar de los avances y cambios a nivel social, sigue existiendo un vacío en el sistema educativo español respecto de la diversidad en el aula y en la sociedad; del respeto a otras realidades e identidades; $y$ del autocuidado, entendido como un espacio personal para pensarse y quererse. El término diversidad se reserva la mayoría de veces para las situaciones en las que están presentes los Otros, lo que no es "Io normal." En el proyecto que compartimos hablamos de realidad social: diversidades a nivel cultural, racial, nacional, religioso, sexual, funcional, de género, de clase, etc. Se plantea si incorporar en el aula la propia historia de vida del profesorado ayuda a generar una empatía y un vínculo con el alumnado capaces de crear un ambiente que favorezca el aprendizaje. En este caso, género, raza y cultura son las tres realidades que protagonizan la identidad de la arteducadora, convirtiéndose en el centro del trabajo.

Fueron rescatadas situaciones de la vida de la arteducadora en las que ser mujer negra y bubi hija de la diáspora cobraba protagonismo y, a través de una investigación aubiográfica, se pasó a comprender una realidad colectiva a partir de la suya propia. Se trata de acercar esa 
historia de vida de la arteducadora al alumnado por medio de estrategias artísticas en contextos educativos. Estas están inspiradas en la realidad que ocultan cada una de esas situaciones personales, el discurso generado por ella como forma de empoderamiento y autocuidado y las referencias bibliográficas y artísticas que fueron apareciendo en el transcurso de la investigación (ver Figura 1).

\section{Figura 1}

Esquema del proceso de investigación que muestra el paso de los recuerdos a las estrategias artísticas para el aula.

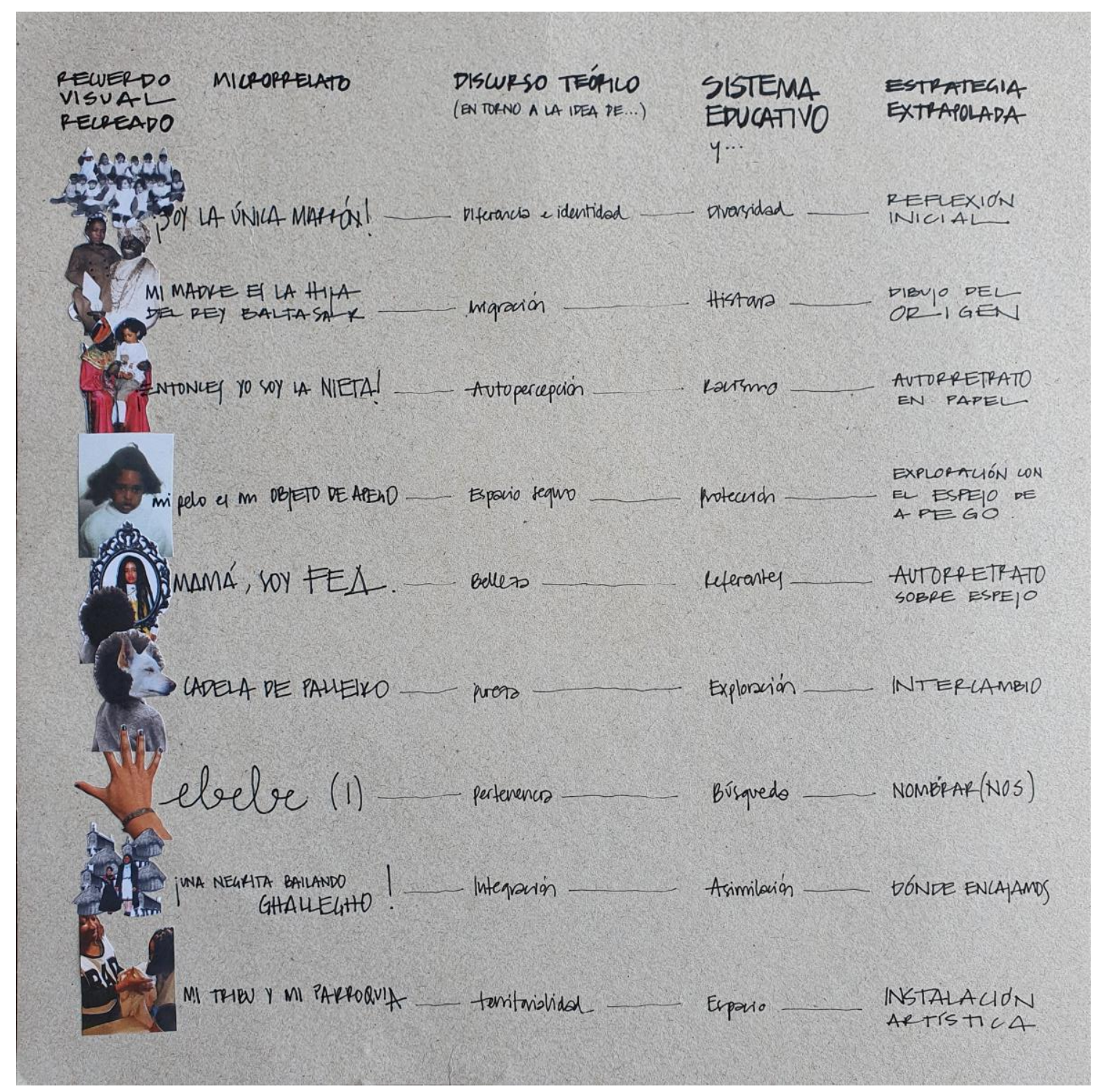

Fuente: archivo personal López-Ganet, 2021. 


\section{Situando las metodologías de investigación educativa basadas en las artes: IBA y ABER}

Esta investigación nace en un contexto artístico de experimentación que bebe de trabajos en los que las artes, la educación y la historia de vida son los ejes principales de la investigación y las herramientas para generar reflexión y cambio. En palabras de Marín,

las metodologías artísticas de investigación confían en que el mestizaje, la simbiosis y la fusión entre dos territorios del conocimiento humano, la investigación científica y la creación artística (tradicionalmente alejada entre sí e incluso opuestos y enfrentados en cuanto a su objetividad, validez y veracidad), produzca resultados fructíferos. $(2012$, p. 16)

A diferencia de muchos campos de investigación que cuentan con una metodología y lenguaje vehicular que pueden resultar algo rígidos, la Investigación Basada en las Artes (IBA) metodología en la que se sitúa el presente trabajo- permite expresar significados a los que no sería posible llegar si no fuese a través de los procesos creativos. Es por ello que Barone y Eisner (2012) definen la IBA como un medio de aproximación mediante el cual "profundizamos y hacemos más complejo nuestro conocimiento sobre algunos aspectos del mundo" (p. 3). De ahí las posibilidades de mayor implicación social que permite esta metodología de investigación y que Finley (2008) describe como "radical, ética y revolucionaria . . . que puede explorar múltiples, nuevos y diversos modos de comprender y de vivir el mundo" (p. 71).

La IBA tiene la posibilidad de exponer a las personas a nuevas ideas, historias o imágenes, y puede hacerlo con el objetivo de fomentar conciencia social. Presentar otras realidades a través de las artes puede ser una forma de promover reflexión y empatía, y así se plantea en este trabajo, que se centra en lo afro, la identidad de la mujer negra y el antirracismo. MesíasLema presenta esta metodología como una forma de investigar acorde con los tiempos posmodernos en la que se toman estrategias y métodos propios de las artes en su sentido más amplio y diverso; de ahí su versatilidad y flexibilidad. Utiliza los procedimientos artísticos para desvelar aspectos que no se harían visibles de otra forma ni en otro tipo de investigación (Hernández, 2011).

Las artes nos permiten visibilizar reflexiones en torno a nuestra identidad, nuestra memoria y nuestra historia de vida y no hay duda de que suponen una importante plataforma para el cambio en aulas y comunidades. La investigación y diversas acciones producidas en el encuentro entre la educación artística contemporánea y la IBA son una acción necesaria para revisar la práctica en educación (De Bruin et al., 2018). Así, el presente trabajo bebe de la 
Investigación Educativa Basada en las Artes (Arts-based Educational Research, [ABER]) una forma de investigar en educación en la que el investigador/a recurre a procedimientos, técnicas, metodologías y estrategias artísticas para compartir su experiencia e interpretarla en un contexto (Mesías-Lema, 2012, 2018, 2019, 2021). Una de las mayores ventajas de la ABER en relación a este trabajo es la reflexividad. Según Weber y Mitchell (2004), esta metodología revela aspectos personales del yo a través de una reflexión profunda con nosotros mismos.

\section{La autobiografía desde la a/r/tography}

Dentro de la $A B E R$, la investigación a/r/tográfica es una metodología que expone las tres identidades que forman parte de toda persona comprometida con esta línea de investigación en Educación Artística: artista, investigador y docente (Springgay et. al, 2008). Con esto se pretende sacar al profesorado del lugar despersonalizado en el que nos tiene la investigación educativa, configurando así un desenvolvimiento para el desarrollo profesional y personal y contextualizando nuestras voces para convertirlas en "historias de vida" (Bolívar, 2014).

Sin embargo, esas identidades múltiples que presenta la metodología a/r/tográfica artista, investigador y docente- no tienen por qué suceder al mismo tiempo ni nos definen profesionalmente, sino que demuestran una serie de intereses y formas de orientar nuestro trabajo e investigación a lo largo de nuestras vidas. Tanto una carrera artística, como docente o investigadora requieren una dedicación y un esfuerzo total que dificultan que se compaginen con otras vertientes profesionales. Se propone que las artes, la educación y la investigación interseccionen continuamente y, con ellas, nuestra capacidad artística, docente e investigadora.

La a/r/tography reconoce la conexión entre la producción, el aprendizaje y el conocimiento en las prácticas artísticas y pedagógicas. Y para hacerlo, recoge las prácticas de artistas, investigadoras/es y quienes enseñan y/o aprenden para seguir una práctica que les lleve a indagar en su propia vida (Irwin et al., 2018). Comprometerse con una Investigación Educativa basada en las Artes con frecuencia significa que los investigadores están inmersos en un viaje de descubrimiento, de aprendizaje sobre sí mismos, así como el aprendizaje de sí mismos con otros. En gran parte de la Investigación Educativa basada en las Artes no hay una distinción siempre entre el investigador y la investigación. En efecto, hay una relación orgánica y viva donde el investigador y la investigación son parte de una intrincada danza que está siempre cambiando. (Sinner et al., 2006, p. 1242)

Muchas vivencias que quedan aisladas en su contexto recobran sentido al encontrarse con otros escenarios de nuestras vidas e identidades; la a/r/tography nos permite experimentar 
lo que nos es aún desconocido (Irwin et al., 2018). Efectivamente, cuando hablamos de $a / r /$ tography hablamos de nuestra triple identidad que nos interconecta como artistas, investigadoras y docentes. Sin embargo, es igual de importante o más nuestra propia historia de vida, cada vivencia, sentimiento y emoción. El planteamiento de esta investigación invita a la autoexploración y autodescubrimiento por medio de las artes, a la empatía y el reencuentro con nosotros mismos (investigadores, arteducadores, profesorado), nuestro pasado como presente, a repensar y valorar nuestra historia y, en ocasiones como las del proyecto que se comparte, a enorgullecernos de quiénes somos. La a/r/tography explora nuestra triple identidad, pero la autobiografía pone en valor esa triple identidad al incluir el Yo que va más allá de cualquier perfil profesional y tendencia investigadora.

\section{La historia de vida como metodología introspectiva clave para la composición autobiográfica}

Recurrimos a nuestra historia de vida para buscar el sentido y justificar, de alguna forma, quiénes somos. Sin embargo, no es lo mismo una vida vivida que el hecho de hacer de una vida una historia. Esto último exige un esfuerzo reflexivo para encontrar un sentido que permita establecer una conexión coherente entre los distintos acontecimientos y experiencias que se consideren relevantes (ver Figura 2). El planteamiento autobiográfico del que se propone que parta la investigación hace que esta evolucione orgánicamente, pudiendo incluir avances que modifiquen su planteamiento inicial -lecturas, conversaciones, reflexiones, referentes artísticos, teóricos o educativos, entre otros- y enriquezcan la investigación.

Las historias de vida explicitan y hacen visibles (para sí mismo y para otros) aquel conjunto de percepciones, intereses, dudas, orientaciones, hitos y circunstancias que han influido y configurado, de modo significativo, quien se es y por qué se actúa como se hace. (Bolívar, 2016, p. 252)

Hablamos de las historias de vida como metodología, pero debemos hacer hincapié y remarcar que en este caso nos estamos refiriendo a las historias de vida del profesorado. Hernández (2011) remarca que la finalidad de la investigación sobre historias de vida es conectar las narrativas personales y biográficas de profesores e investigadores con su contexto sociocultural, histórico e institucional. Asegura que esta conexión es la que hace posible que lo individual se convierta en colectivo. Entiendo entonces que el alumnado también podría generar esa conexión.

El trabajo del investigador y profesor Ivor Goodson (2012) invita al estudio de las trayectorias personales y profesionales del profesorado, entendiendo que el relato de las 
reflexiones que puedan hacer sobre su propia vida personal y profesional previa se relaciona directamente con sus pensamientos y acciones profesionales presentes. Esos relatos, afirma el autor, son construcciones sociales situadas en un tiempo y un lugar con un trasfondo histórico y cultural. El planteamiento individual e íntimo de la autobiografía nos recuerda que no es posible universalizar la investigación y cada proceso metodológico. Tener realidades distintas hace que cuestionemos, interpretemos y evaluemos lo que nos rodea también de manera distinta.

\section{Figura 2}

Fotos de carné sacadas a lo largo de mi vida.
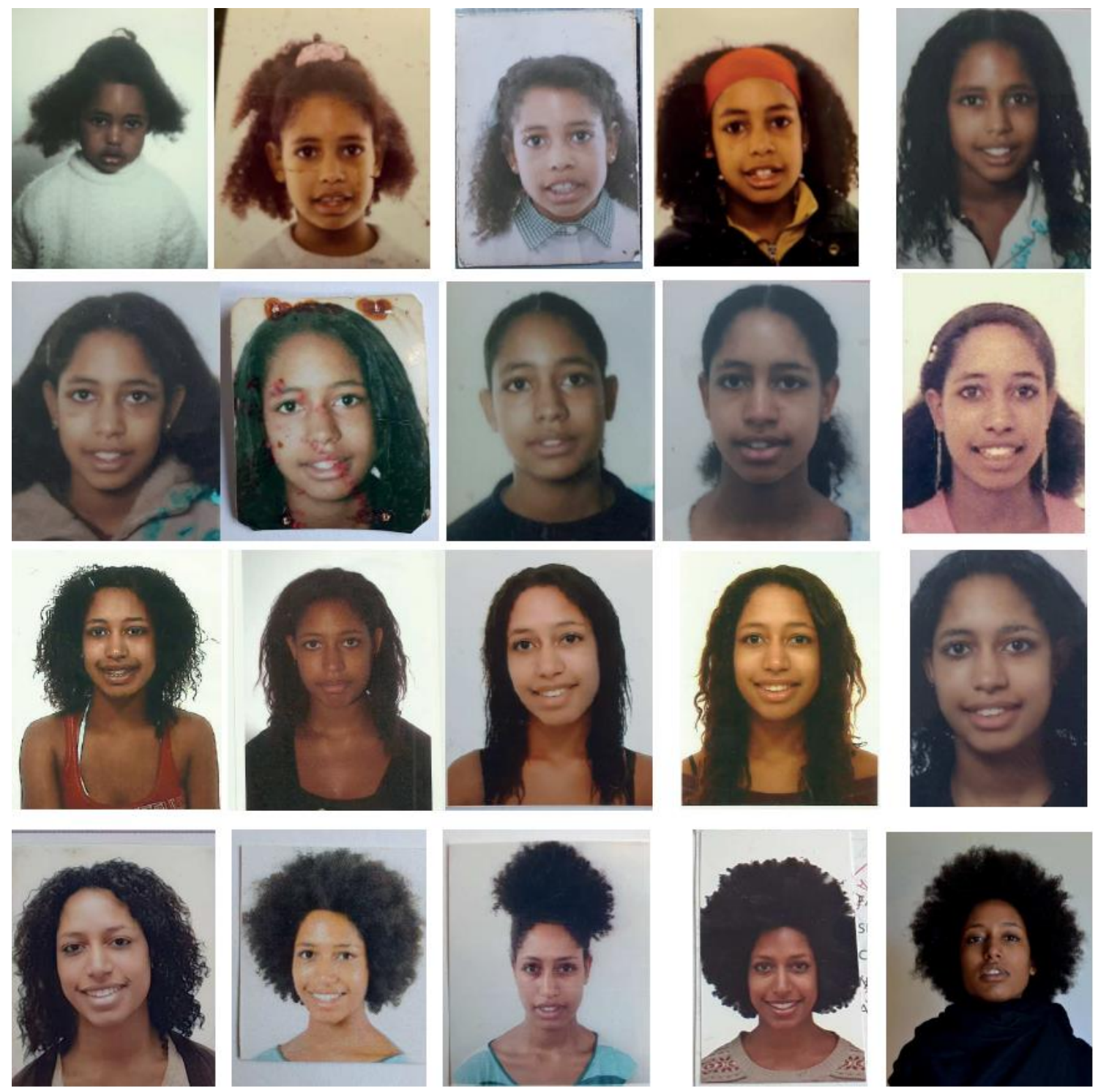

Fuente: archivo personal López-Ganet.

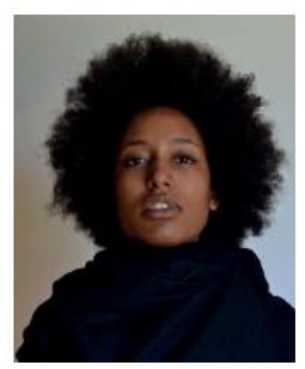


Hablamos de una realidad colectiva desde lo personal, porque lo vivimos y nuestra experiencia es lo primero que podemos compartir. Lo sacamos para liberarnos, para sanarnos y hasta concienciarnos. Así lo hacemos en este proyecto autobiográfico con recuerdos personales que, como sugiere Kilomba (2019) con los episodios de racismo cotidiano, "no son historias personales o lamentos íntimos, sino historias de racismo" (p. 57). La autora apela por "una epistemología que integre lo personal y lo subjetivo en el discurso académico, pues todas/os hablamos de un tiempo y de un lugar específicos, de una historia y de una realidad específicasno hay discursos neutros" (p. 58). La descolonización del saber se producirá a base de discursos tan políticos como personales y poéticos, capaces de producir un conocimiento alternativo emancipador.

\section{Instrumentos visuales para la introspección autobiográfica como metodología en la ABER: Diario visual, archivo fotográfico y audiovisual familiar y archivo doméstico}

Los instrumentos para lograr desde nuestro planteamiento cohesión y coherencia en una investigación que parte de nuestra historia de vida deben estar ligados a nuestro campo: el de las artes y la Educación Artística. Así, estos instrumentos visuales son el medio para lograr la introspección personal que nos permita entrar en la academia y en las aulas desde lo personal. El diario, el archivo fotográfico familiar o la recreación de recuerdos pueden embarcarnos en un viaje a través de la memoria por medio de las artes. La incorporación de la producción artística en la búsqueda permite experimentar con otros lenguajes como el collage, la performance, la danza, el cine, el vídeo o la fotografía, para así obtener modos alternativos de búsqueda, representación de la investigación y producción de conocimiento.

El trabajo que se comparte desde la realidad negra consiste en un estudio autobiográfico a través de fotografía y vídeo domésticos, proceso que bebe de la post-fotografía. La era digital en la que estamos inmersos ha traído consigo la "superabundancia visual" de la que habla Fontcuberta (2016, p. 7), y de la fotografía que fluye en este entorno hablamos cuando hablamos de postfotografía: un nuevo lenguaje en el que la imagen ha entrado en nuestra forma de relación con los demás, pero también con nosotros mismos. Fontcuberta (2016) añade un punto importante a la descripción de la postfotografía afirmando que se desmaterializa la autoría, se disuelven las nociones de originalidad y propiedad (ver Figura 3). Crear en esta era, por tanto, puede conllevar la reencarnación de las imágenes, a su reutilización y reinvención. 


\section{Figura 3}

\section{Carné del Xabarín Club}

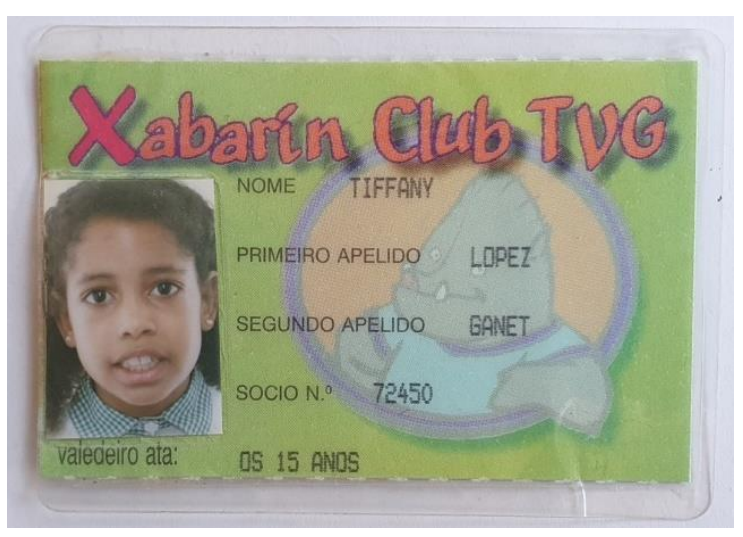

Fuente: archivo personal López-Ganet (1994)

Fotografía en este caso es memoria, una forma de recordar. La organización, diálogo y análisis visual de estas fotos y vídeos son la clave para poder construir y compartir a partir de este archivo. A pesar de que las imágenes se presentan como hechos reales, son creadas a partir de un proceso selectivo que las ordena, clasifica, elige y nombra (Desai, 2019) en relación a una identidad, una historia y/o un contexto. En función de cómo las agrupemos, de qué intereses se muestren más repetidamente y qué narrativas se creen, estaremos sacando a la luz una introspección personal, íntima y única capaz de armar una metodología artística educativa que vaya mucho más allá (ver Figura 4).

\section{Figura 4}

Papá, yo, mamá

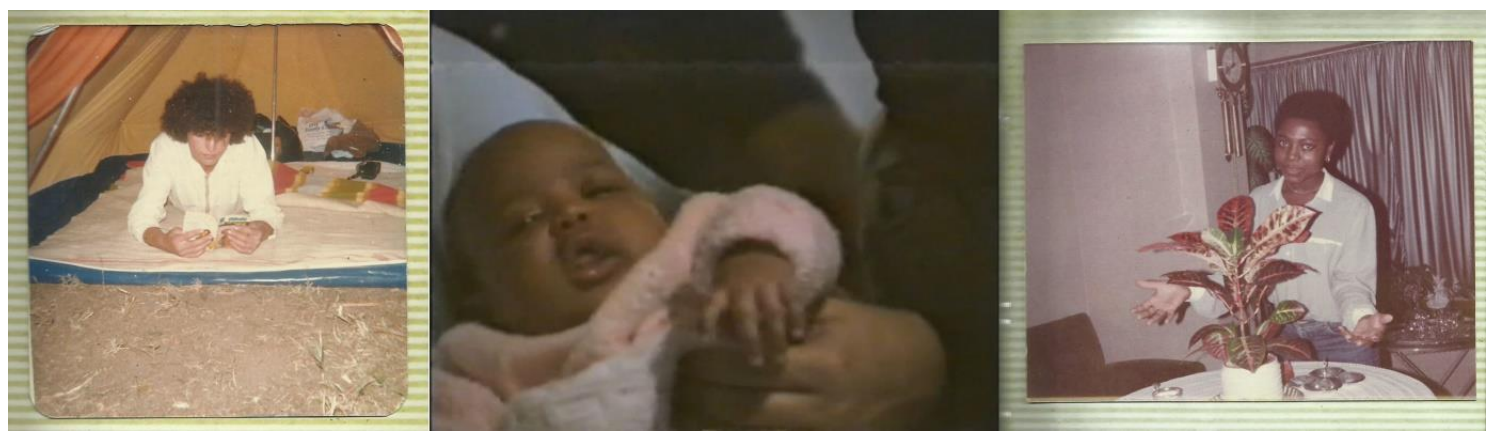

Fuente: archivo personal López-Ganet (1980, 1990, 1980)

Ese carácter doméstico de las fotos y vídeos se traslada a toda una forma de investigar, que mantiene la intimidad, privacidad, emoción y sensibilidad de un proceso orgánico como es el trabajar con una historia de vida. Pero no solo las imágenes impresas hablan de recuerdos y 
memoria, sino los objetos que nos acompañan, las anécdotas que cuentan o cada escena recreada en nuestros diarios. El diario visual que recopila nuestra autobiografía se convierte en un objeto artístico, en una recolección no solo de recuerdos, emociones e ideas descritas en papel, sino en la materialización de todo ello. Aunque sea un planteamiento personal, son muchas las personas que se podrían identificar con él de alguna manera ya que lo autobiográfico no siempre es individual, sino colectivo. De alguna forma, este tipo de metodologías artísticas aplicadas a la investigación educativa refleja la mirada de los otros en nuestra propia introspección.

En la columna de Juan Santos (2019) de la revista Clavoardiendo se muestra el trabajo de Ana Casas Broda (Santos, 2019). La artista granadina en su obra Cuadernos de Dieta (1991) recogió durante ocho años anotaciones de todo lo que comía y fotografías regulares de la evolución de su cuerpo. Esas fotos forman parte de un proceso íntimo, no fueron hechas para ser mostradas. La introspección personal que hagamos como motor de nuestra investigación educativa basada en las artes puede o no estar pensada para ser mostrada. No obstante, al ser visualizada, se convierten en imágenes propias de la producción artística e investigadora que dota de rigor científico al proceso indagador. Así, las imágenes estarán o no impregnadas de intención y ocultarán o no partes de la historia. Santos (2019) nos recuerda que la distancia que tomamos con el relato autobiográfico es otro elemento a tener en cuenta; y es que, aunque pueda parecer contradictorio, podemos convertirnos en espectadores de nuestro propio diario y este está impregnado de emociones que se interpondrán en nuestra lectura.

\section{Proximidad a la arteterapia por el trabajo íntimo y personal que supone una introspección personal a partir de la memoria}

La introspección personal y autobiografía como metodología visual pretende convertirse en una herramienta colectiva, pero nace como centro del propio autocuidado de la persona investigadora: su medio para preguntarse quién es, qué necesita y hacia dónde quiere ir. A pesar de la relación con todo lo que nos rodea y su influencia en nosotros, somos responsables de nuestro propio bienestar tanto a nivel individual como en comunidad. Al igual que varían nuestros estados de ánimo y momentos vitales, también lo hacen nuestras necesidades y nuestras realidades de una persona a otra, de ahí que no exista la receta mágica que garantice el éxito siempre y para todo el mundo por igual.

El conflicto es algo constante en la investigación autobiográfica y tal y como afirma López Fernández-Cao (2011), debe entenderse como un "elemento común del desarrollo humano que 
une cognición y emoción" (p. 14). La autora afirma que el arte a veces nos ayuda no tanto a conocer la realidad sino la nuestra propia, nuestro paisaje interior: "aquel que nadie conoce más que nosotros y nosotras, aquel que no le interesa más que a nosotros mismos y solo nosotros contemplamos" (p. 19).

Planteamientos como el de esta investigación suponen un aprendizaje y empoderamiento que nos permite ser capaz de repetir ese ejercicio de pensarnos de forma sana y entendiendo que no estamos ante una situación aislada; nos acerca, efectivamente a ese paisaje interior íntimo y privado. De la sensación de soledad al mostrar nuestras historias de vida como individuales y únicas a la creación de lazos y comunidad al vernos reflejados en las del resto y comprobar que no estamos solos y solas. Más que arteterapia, el planteamiento de esta investigación habla de autocuidado: conocerse y conocer la historia para quererse; es tratar el pasado, pero también trabajar el presente y prepararse para el futuro tanto a nivel individual como colectivo.

\section{Autoetnografía y narrativas identitarias}

Nuestra historia está cargada de un gran componente cultural, social, antropológico y etnográfico. ¿Todas las autobiografías son autoetnografías? ¿Cualquier historia de vida es antropológica? ¿También el cine de Philip Hoffman o Jonas Mekas, las performances de Marina Abramović o la fotografía de Vivian Maier? ¿Siempre que hablamos de vidas y personas estamos entrando en ese campo de investigación o solo cuando el objeto de estudio son o somos los Otros -entendidos como lo diferente, lo que se sale de la norma--?

Al ahondar en quiénes somos estamos reflexionando acerca de nuestra identidad y el sentido de pertenencia a partir de nuestra historia de vida en forma de imágenes. Disciplinas como la antropología visual, la etnografía visual o la sociología visual también entienden la imagen como principal objeto de estudio y medio para comunicar datos, contenidos y resultados. Sin embargo, como señala Mesías-Lema (2012), a diferencia de las investigaciones artísticas, estas disciplinas de las ciencias sociales no entienden la imagen como un modo de producir nuevo conocimiento.

Formas de investigación como la antropología, la etnografía o la sociología surgen en unas condiciones protagonizadas por la colonización, dominación y explotación, por lo que arrastran con ellas una forma de mirar a la otra persona, a pesar de las revisiones. La idea de estudiar al otro implica un posicionamiento en el que posiblemente solo uno tenga voz y poder de decisión, dando respuesta a su propio interés; o la simple curiosidad. Para muchos etnógrafos la fotografía 
y el vídeo son herramientas para mantener la conexión con el tema a estudiar por ser ajeno a ellos. Pero en este caso, las imágenes planteadas como instrumentos de investigación artística no son un anexo, son la investigación en sí que, además, hablan en primera persona. Las fotografías, los vídeos, los fotomontajes y collages, las performances, danzas o cualquier otro recurso son el punto de partida, la herramienta de búsqueda y el objeto final.

La antropología visual también se puede entender como una metodología que emplea la fotografía para acceder a narrativas identitarias. En sus orígenes, se centraba en cómo la percepción de lo real se rige por prejuicios y estereotipos que sesgan la percepción fotográfica. Sin embargo, a mediados de los años 80 se pasa a hablar de "construcción narrativa de la identidad" en lugar de prejuicios y estereotipos (Vila, 1997, p. 125). Esta vertiente de la antropología visual nos permite entender que la persona investigadora está en sus imágenes sea cual sea el instrumento o instrumentos al que haya recurrido para su introspección personal-, pero solo ve lo que le permite la construcción narrativa de su identidad; se ve en esas imágenes con todas sus historias vividas, recuerdos positivos y heridas. Ser el propio investigador el que trabaja con las imágenes le permite ver más allá, conectar momentos y aunar la experiencia.

Para entendernos como personas, nuestras vidas tienen que ser algo más que una serie aislada de eventos. $Y$ es aquí precisamente donde intervienen las narrativas: transformando eventos aislados en episodios unidos por una trama (Sommers, 1992). Esa trama argumental que ordena nuestra realidad es la propuesta que recoge esta investigación, extrayendo aquellos eventos que contribuyen de forma significativa a dar sentido a la construcción de nuestra historia.

La objetividad tantas veces cuestionada en la investigación basada en las artes y cualquier otra innovación que se salga de la norma también es algo a tener en cuenta cuando se plantea una metodología autobiográfica, única, íntima y personal. Sin ir más lejos, la objetividad de la fotografía en sí también está sesgada por nuestra forma hegemónica de ver la realidad desde el siglo XV; y por la particularidad de cómo cada persona lee esa realidad que aparece en la fotografía debido a su narrativa identitaria, a sus argumentos y al personaje construido de su "yo" y de los "otros" (Vila, 1997). Se propone incluir la narrativa identitaria para que las fotos tengan sentido en relación a la vida, al presente y al futuro, ya que la foto ya no es solo pasado. Tal y como afirma Vila (1997), "el proceso de construcción identitaria está caracterizado por un continuo movimiento de ida y vuelta entre contar y vivir, entre narrar y ser" (p. 128). 
El grueso del tipo de investigaciones que plantea el presente trabajo está formado por las experiencias que recuerda el arteducador y/o investigador, que arman su narrativa identitaria; pero lo más interesante del trabajo es que una vida individual está sirviendo de hilo conductor para analizar su contexto, realidad histórica y toda la comunidad que aúne. Esta reflexión nos acerca a la autoetnografía, metodología que incluye los relatos personales y autobiográficos y las experiencias de la persona investigadora situándolos en un contexto social y cultural (Blanco, 2012). En líneas generales, estamos planteando algo similar; sin embargo, los estudios de las ciencias sociales, y en especial de la etnografía, se han centrado en el Otro, entendido como un ser extraño, primitivo y extranjero. Una visión y enfoque colonialista que refuerza lo tan diferente y exótico que es lo investigado en comparación con los académicos.

El prefijo auto- cambia las cosas, permitiendo eliminar esa relación con el otro y centrando la responsabilidad de compartir la historia y de cómo hacerlo en uno mismo. Chang (2008) en su obra Autoethnography as method recoge las ventajas e inconvenientes de la metodología autoetnográfica: la principal fuente de datos es el propio investigador ya que tiene acceso a datos familiares e íntimos, permite una comprensión de uno mismo y de los demás, es un trabajo que nos transforma y transforma al resto y permite abandonar ciertos convencionalismos metodológicos.

Las críticas que se le hacen a la autoetnografía son, desde nuestro punto de vista, precisamente sus puntos fuertes, por conseguir alejarse mínimamente del resto de ciencias sociales que arrastran tendencias colonialistas: la especial atención del "auto" con respecto al resto, el peso de la narración personal frente a la interpretación cultural, el recurrir constantemente a la memoria sin necesidad de estrategias de contraste y validación de la información o la libertad a la hora de lo ético y lo confidencial. No por ser personal, no por ser escrita en primera persona y no por ser subjetiva existe una pérdida de valor académico.

Todos estos planteamientos nos han servido para reflexionar acerca de cómo nos pensamos y cómo trabajamos con nuestra propia historia de vida. Pero también debemos prestar atención a nuestro papel como arteducadores y arteducadoras y a cómo analizamos y usamos lo producido y compartido con el alumnado. Así, en el proyecto autobiográfico que acompaña a la investigación, buscamos partir de lo individual para acercarnos a lo grupal, fortaleciendo así el bienestar de cada alumno/a y el de todos/as, independientemente de su condición, procedencia o realidad. Pretendemos de este modo generar conexiones entre lo particular y lo universal y entre lo personal y lo colectivo con las artes, entendiendo que de ese modo se podrá engendrar un proyecto cultural, accesible y comunitario, desde posicionamientos críticos (Escaño, 2018). 


\section{Conclusión: creación de estrategias artísticas para contextos educativos desde una introspección personal}

A raíz de la investigación autobiográfica (archivo visual e historia de vida en relación a las imágenes domésticas) así como los hallazgos realizados en torno a los episodios de racismo cotidiano vividos, se llevaron a cabo estrategias artísticas en otros contextos-desde A Coruña hasta Malabo (Guinea Ecuatorial), pasando por Ottawa (Canadá) o Anantapur (India)-. Extrapolando recuerdos personales, se generaron estrategias con estudiantes para crear una conciencia, sensibilización y empatía hacia las exclusiones vividas por otros. Supone una transferencia de la investigación al campo de acción activista y antirracista en la enseñanza y aprendizaje de las artes, en distintos territorios y con distintas edades (educación primaria, secundaria, escuela de artes y futuros docentes).

Se acerca la historia individual de la arteducadora como mujer negra en España - y la colectiva que cuenta esta a su vez-, se comparte con el alumnado, se busca generar conciencia social a partir de ella y recoger impresiones y reflexiones desde las acciones artísticas iniciadas desde lo personal. Lo orgánico y versátil de las vivencias de una mujer negra, bubi y gallega hace de esta investigación una posible referencia: lo íntimo del archivo fotográfico doméstico, la autoexploración a través de la cámara, los viajes de regreso al origen, cada intervención en el aula (en A Coruña, Ottawa, Anantapur y Malabo) y la construcción de un discurso a partir de todo lo que envuelve esa historia de vida.

Cada uno de los recuerdos visuales y correspondientes producciones artísticas a partir de ellos - fotografías, vídeos, collages o performances - fueron el motor de un discurso que, junto con referencias bibliográficas y artísticas, llevaron a crear cada estrategia artística extrapolada para poner en práctica en el aula. De manera orgánica, y tal y como sucedió en la búsqueda personal, esas estrategias salidas de la propia experiencia de la arteducadora van de lo más individual a lo más colectivo, llevándose a sí misma y al alumnado a explorar desde lo más íntimo y privado hasta crear lazos y compartir en comunidad.

Un viaje al origen de cada historia familiar y personal a través del dibujo y de la recopilación de recuerdos; un autorretrato sobre un espejo; un intercambio y superposición de identidades para ponerse en la piel del otro; un cuestionamiento de lo que nos rodea, una búsqueda de un espacio especial en la escuela que signifique para el grupo, la creación de una instalación artística como motor del colectivo y una reflexión final que recoja todo el proceso; así se compartió la historia. Una secuencia ordenada de acciones artísticas que, según la realidad 
del contexto en el que se pone en práctica, genera distintas sensaciones, emociones, producciones artísticas, impresiones en el alumnado y en la arteducadora; pero siempre desde la empatía y el respeto.

Muchas de las reflexiones personales han surgido a raíz de las experiencias en las aulas (ver Figuras 5, 6 y 7), los avances en la investigación se han visto condicionados por lo descubierto a nivel personal, familiar y comunitario, y todo ello ha influido en la evolución de la autopercepción y autorrepresentación. Lo que pasaba en cada uno de los niveles del trabajo (investigador, educativo, artístico y personal) generaba un cambio en el resto: así, una lectura podía suponer un antes y un después en la interpretación de lo que nos rodea y de nosotros mismos, algo que podía hacer cambiar el planteamiento de la puesta en práctica. Ahí reside el poder de lo orgánico e íntimo de un proyecto autobiográfico. Lo personal también es artístico y la investigación no existe, en este caso, sin las vivencias, fotografías, reflexiones o lo sucedido en las aulas.

\section{Figuras 5}

Raíces que asoman en la Universidad de Ottawa

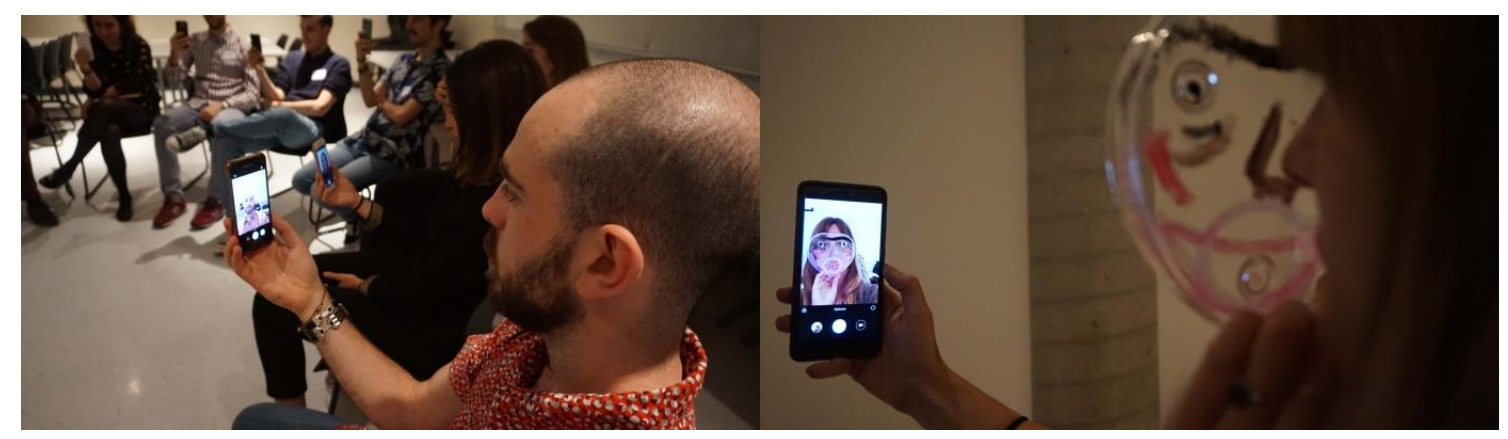

Fuente: archivo personal López-Ganet, 2018.

\section{Figuras 6}

\section{Raíces que asoman en Anantapur (India)}

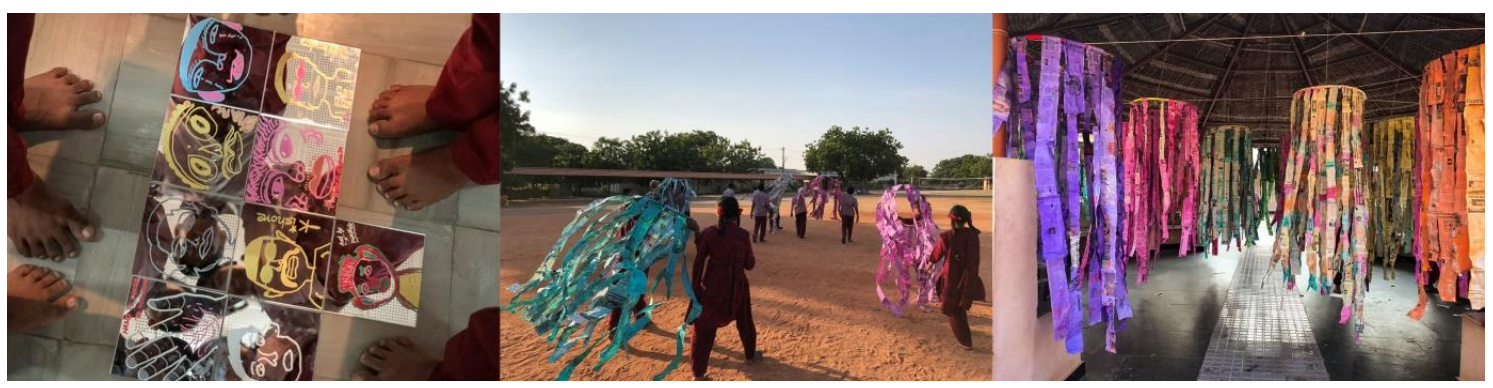

Fuente: archivo personal López-Ganet, 2018. 


\section{Figura 7}

Raíces que asoman en la Escola de Arte Superior de Deseño Pablo Picasso.

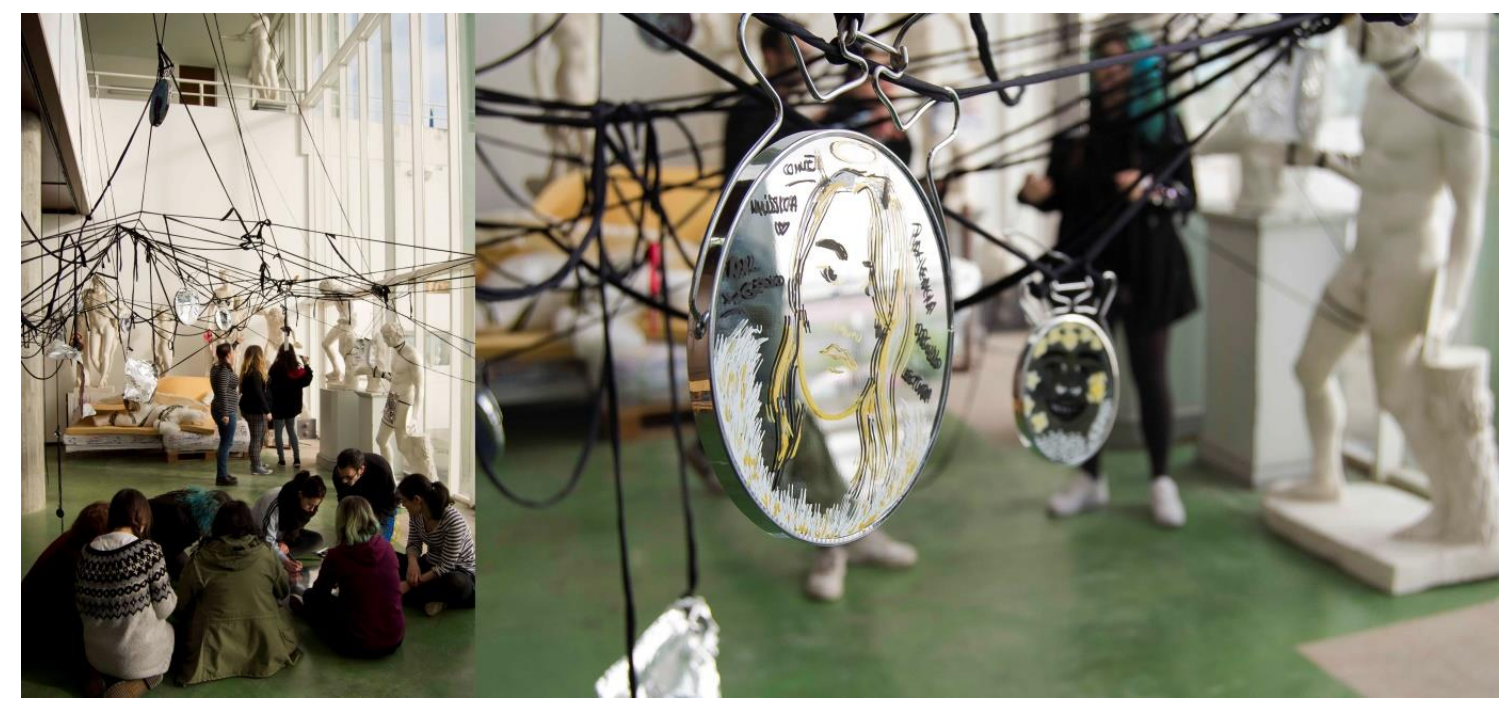

Fuente: archivo personal López-Ganet, 2018.

\section{Referencias}

Barone, Tom y Eisner, Elliot (2012). Arts Based Research. [La investigación basada en las artes]. Sage.

Bolívar, Antonio (2014). Las historias de vida del profesorado. Voces y contextos. Revista Mexicana de Investigación Educativa, 19(62), 711-734.

Bolívar, Antonio (2016). Las historias de vida y construcción de identidades profesionales. En M. H. Abrahão, L. Frison y C. Barreiro (Eds.), Nova Aventura (Auto)Biográfica [Nueva Aventura (Auto)Biográfica] (pp. 251-287). EdiPUCRS.

Casas-Broda, Ana (1986-1994). Cuadernos de dieta. https://www.anacasasbroda.com/textocuadernos-dieta

Chang, Heewon (2008). Autoethnography as method [Autoetnografía como método]. Left Coast Press.

De Bruin, Leon R.; Burnard, Pamela y Davis, Susan (2018). Connecting Creativities in the Arts: Exploring Diverse Creativities in Arts Practice and Arts-Based Research [Conectando creatividades en las artes: explorando creatividades diversas en la práctica artística y la Investigación Basada en las Artes]. En L. R. De Bruin, P. Burnard y S. Davis (Eds.), Creativities in Arts Education, Research and Practice: International Perspectives for the Future of Learning and Teaching [Creatividad en Educación Artística, investigación y 
práctica: perspectivas internacionales para el futuro del aprendizaje y la enseñanza] (pp. 1-11). Brill Sense.

Desai, Dipti (2019). Cultural Diversity in Art Education [Diversidad cultural en Educación Artística]. En R. Hickman (Ed.), The International Encyclopedia of Art \& Design Education [La enciclopedia internacional de educación de las artes y el diseño] (pp. 1023-1043). Wiley.

Escaño, Carlos (2018). Educación hacker: una pedagogía crítica (inter)creativa para los comunes del conocimiento. En R. Aparici, C. Escaño, D. García (Coords.), La otra educación: pedagogías críticas para el siglo XXI (pp. 53-64). UNED.

Finley, Susan (2008). Arts-Based Research [Investigación basada en las artes]. En J. Gary Knowles y Ardra L. Cole (Eds.), Handbook of the Arts in Qualitative Research: Perspectives, Methodologies, Examples, and Issues [Manual de las artes en la investigación cualitativa: perspectivas, metodologías, ejemplos y cuestiones] (pp. 71-81). Sage.

Goodson, Ivor (2012). Developing Narrative Theory: Life Histories and Personal Representation [Desarrollando la teoría narrativa: historias de vida y representación personal]. Routledge. Hernández-Hernández, Fernando (2011). Las historias de vida en el marco del giro narrativo en la investigación en Ciencias Sociales: los desafíos de poner biografías en contexto. En F. Hernández, J. M. Sancho y J. I. Rivas (Coord.), Historias de vida en educación: biografías en contexto (pp. 13-22). Universitat de Barcelona/Esbrina. http://hdl.handle.net/2445/15323 Irwin, Rita; LeBlanc, Natalie; Ryu, Jee Yeon y Belliveau, George (2018). A/r/tography as Living Inquiry [A/r/tografía como investigación vital]. En P. Leavy (Ed.), Handbook of Arts-Based Research [Manual de la Investigación Basada en las Artes]. The Guilford Press.

Kilomba, Grada (2019). Memórias da plantação: Episódios de racismo quotidiano [Memorias de la plantación: Episodios de racismo cotidiano]. Orfeu Negro.

López Fernández-Cao, Marián (2011). Memoria, ausencia e identidad. El arte como terapia. Eneida.

López-Ganet, Tiffany (2017). Microrrelatos autoetnográficos. Historias de vida interculturales para la transformación social. Revista de Estudios e Investigación en Psicología y Educación, (04), 140-144. https://doi.org/10.17979/reipe.2017.0.04.2700

López-Ganet, Tiffany (2017). Raíces que asoman. Creación de estrategias artísticas a través de una introspección personal. Revista de Estudios e Investigación en Psicología y Educación, (04), 089-094. https://doi.org/10.17979/reipe.2017.0.04.2601

López-Ganet, Tiffany (7 de octubre de 2018). Explorando lo invisible: proyecto de Educación Artística en el High School for Inclusive Education. Communiars. https://communiars.org/ 
2018/10/07/explorando-lo-invisible-proyecto-de-educacion-artistica-en-el-high-schoolfor-inclusive-education/

Marín, Ricardo (2012). Las Metodologías Artísticas de Investigación y la investigación educativa basada en las Artes Visuales. En J. Roldány R. Marín (Ed.), Metodologías artísticas de Investigación en educación (pp. 14-39). Aljibe.

Mesías-Lema, José María (2012). Fotografía y educación de las artes visuales: el fotoactivismo educativo como estrategia docente en la formación del profesorado [Tesis doctoral]. Universidad de Granada. http://hdl.handle.net/10481/23310

Mesías-Lema, José María (2017). Art teacher training: A photo essay [La formación del profesorado de artes: un foto-ensayo]. International Journal of Education through Art, 13(3), 395-404. https://doi.org/10.1386/eta.13.3.395_1

Mesías-Lema, José María (2018). Artivism and social conscience: Transforming teacher training from a sensibility standpoint [Artivismo y compromiso social: Transformar la formación del profesorado desde la sensibilidad]. Comunicar, 26(57), 19-28. https://doi.org/10. 3916/C57-2018-02

Mesías-Lema, José María (2019). Artistas habitantes: una metodología contemporánea, participativa y colectiva en Educación Artística. Observar, 13, 74-104. https://www.obser var.eu/index.php/Observar/article/view/104

Mesías-Lema, José María (2019). Educación Artística Sensible. Cartografía contemporánea para arteducadores. Graó.

Mesías-Lema, J. M. (2021). La investigación educativa basada en las artes ya no necesita mártires: Un pequeño homenaje a la práctica docente de Mark Rothko. IJABER. International Journal of Arts-Based Educational Research, 1(1), 1-6. https://doi.org/10.17979/ijaber.2021.1.1.7617

Santos, Juan (2019). Día a día: De Ana Casas a Kaylynn Deveney y Albert Hastings. Clavoardiendo. https://clavoardiendo-magazine.com/columnas-series/autobiografias-visuales/dia-a-diade-ana-casas-a-kaylynn-deveney-y-albert-hastings/

Sinner, Anita; Leggo, Carl; Irwin, Rita; Gouzouasis, Peter y Grauer, Kit (2006). Art-Based Educational Research Dissertations: Reviewing the practices of new scholars [Tesis de Investigación Educativa Basada en las Artes: revisando las prácticas de nuevos académicos]. Canadian Journal of Education, 29(4), 1213-1270. https://journals.sfu.ca/ cje/index.php/cje-rce/article/view/2939

Sommers, Margaret R. (1992). Special Section: Narrative Analysis in Social Science, part 2. Narrativity, Narrative Identity, and Social Action: Rethinking English Working-Class 
Formation [Sección especial: análisis narrative en las ciencias sociales, parte 2. Narratividad, identidad narrative y acción social: repensando la formación de la clase trabajadora inglesa]. Social Science History, 16(4), 591-630. https://doi.org/10.2307/1171314

Springgay, Stephanie; Irwin, Rita; Leggo, Carl y Gouzouasis, Peter (Eds.) (2008). Being with $A / r /$ tography [Siendo con $\mathrm{A} / \mathrm{r} /$ tography]. Sense Publishers.

Vila, Pablo (1997). Hacia una reconsideración de la antropología visual como metodología de investigación social. Estudios sobre las Culturas Contemporáneas, 3(6), 125-167.

Weber, Sandra y Mitchell, Claudia (2004). About Art-Based Research [Sobre la Investigación Basada en las Artes]. En J. Loughram, M. Hamilton, V. Laboskey y T. Rusell (Eds.), International Handbook of Self-Study of Teaching and Teacher Education Practices [Manual internacional de autoformación en enseñanza y prácticas docentes]. Kluwer Press.

Fecha de recepción: 31 de abril de 2021. Fecha de revisión: 25 de junio de 2021. Fecha de aceptación: 26 de junio de 2021. Fecha de publicación: 1 de julio de 2021. 